\title{
MERDEKA 74" (MINAPADI BERSAMA DENGAN IKAN LOKAL 7 SPESIES DAN 4 LEGOWO)
}

\author{
MERDEKA “74" (Minapadi Together With 7 Species And Local Fish \\ 4 Legowo)
}

\author{
Mahendra $^{1 *}$, Zuriat ${ }^{2)}$, Alaudin'), Fazril Saputra'), Sufal Diansyah'), Citra Dina Febrina'), Farah \\ Diana1), Muhammad Arif Nasution"), Zulfadhli 1) Fitria Rahmayanti') \\ ${ }^{1}$ Program studi Akuakultur, Fakultas Perikanan dan Ilmu Kelautan, Universitas Teuku Umar \\ ${ }^{2}$ Progaram studi Perikanan, Fakultas Perikanan dan IImu Kelautan, Universitas Teuku Umar \\ ${ }^{3}$ Progaram studi IImu Kelautan, Fakultas Perikanan dan IImu Kelautan, Universitas Teuku Umar \\ ${ }^{4}$ Progaram studi Sumberdaya Akuatik, Fakultas Perikanan dan IImu Kelautan, Universitas Teuku Umar \\ Jl. Alue Peunyareng, Meureubo, Aceh Barat, Provinsi Aceh, Indonesia, \\ Korespondensi: mahendra@utu.ac.id
}

\begin{abstract}
ABSTRAK
Tujuan Pengabdian ini adalah untuk mengaplikasikan hasil penelitian riset tim pengusul untuk pemberdayaan masyarakat di Kecamatan Pante Ceureumen, Aceh Barat. Penerapan hasil riset dilakukan pada program kegiatan MERDEKA 74" (Minapadi Bersama Dengan Ikan Lokal 7 Spesies Dan 4 Legowo) yang merupakan sistem menanam padi dengan budidaya ikan di dalam satu areal persawahan secara bersamaan. Program ini bertujuan untuk meningkatkan pendapatan hasil petani dengan produktifitas hasil padi yang tinggi dan meningkatkan produksi ikan lokal. Kegiatan dilakukan selama 6 bulan bertempat di Kecamatan Pante Ceureumen Aceh Barat. Hasil yang diamati meliputi produksi padi dan produksi ikan pada sistem minapadi. Produksi padi tanam legowo 2 : 1 memberikan pengaruh nyata terhadap parameter hasil produksi padi yaitu (16.17 kg/ha). Sedangkan Produksi ikan yang di budidayakan (7 spesies) yaitu ikan serukan, ikan bileh, ikan nila, ikan mas, ikan patin, ikan lele dan udang galah. Ke-7 spesies tersebut mampu berkembang dan dibudidayakan dengan baik.
\end{abstract}

Kata kunci: ikan lokal, legowo, minapadi

\section{ABSTRACT}

The purpose of this Community Service is to apply the research results of the proposer team's research for community empowerment in Pante Ceureumen District, West Aceh. Research results are applied to the activity program MERDEKA 74 "(Minapadi Together with Local Fish 7 Species and 4 Legowo) which is a system of planting rice by cultivating fish in one rice field simultaneously. This program aims to increase farmers' income with high rice yield productivity and increase local fish production. The activity was carried out for 6 months at the Pante Ceureumen District, West Aceh. The results observed included rice production and fish production in the Minapadi system. The production of 2: 1 legowo planted rice has a significant effect on the parameters of rice production, namely $(16.17 \mathrm{~kg} / \mathrm{Ha})$. Meanwhile, the production of cultivated fish (7 species) are catfish, bileh fish, tilapia, goldfish, catfish, catfish and giant prawns. The 7 species are able to develop and be cultivated well.

Key words: local fish, legowo, minapadi

\section{PENDAHULUAN}

Usaha-usaha pembudidaya ikan di Kabupaten Aceh Barat sudah mulai berkembang, namun sayangnya jenis yang dipelihara adalah ikan-ikan asing hasil 
introduksi dari luar Aceh dan bahkan luar negara. Kondisi ini memberikan tekanan kepada populasi ikan asli setempat. Sementara itu Aceh juga memiliki potensi ikan asli yang tidak kalah baik dari segi jumlah maupun kualitasnya, misalnya ikan serukan (Osteochilus Vittatus), dan udang galah (Macrobracium rosenbergii) (DKP Aceh, 2015). Menurut hasil riset tim peneliti bahwa ikan-ikan lokal yang berhasil ditingkatkan produksinya meliputi ikan serukan (Mahendra dan Supriadi, 2019), udang galah (Mahendra, 2015), udang pisang (Mahendra dan Gazali, 2017), ikan bileh (Zulfadhli dan Fadhillah, 2019) dan ikan gabus lokal (Saputra dan Mahendra, 2018),

Potensi dan peluang usaha bagi calon pengusahan sangat potensial, karena tempat di lokasi kegiatan tersebut sangat strategis, yaitu memiliki sumber air irigasi yang kebutuhannya selalu kontinyu dan rata-rata pekerja sumberdaya manusia di daerah tersebut adalah petani dan pembudidaya ikan, namun kegiatannya hanya mengerjakan satu prioritas saja tanpa intensifikasi untuk meningkatkan pendapatan hasil petani dan pembudidaya ikan.

Permasalahan prioritas mitra kelompok tani adalah belum mendapatkan ilmu dan sains yang dapat menjadikan calon pengusaha untuk menjadi pengusaha dengan potensi daerah yang ada. Solusi yang disepakati bersama dalam kegiatan ini adalah memanfaatkan potensi yang ada dengan menerapkan MERDEKA 74" (Minapadi Bersama Dengan Ikan Lokal 7 Spesies Dan 4 Legowo) yang merupakan sistem menanam padi dengan budidaya ikan di dalam satu areal persawahan secara bersamaan.

\section{METODE PELAKSANAAN Lokasi Kegiatan}

Pelaksanaan kegiatan ini dilakukan di areal persawahan Desa Lango Kecamatan Pante Ceureumen Kabupaten Aceh Barat Provinsi Aceh.

\section{Bahan dan Alat}

Bahan yang digunakan dalam kegiatan ini adalah: benih padi MAPAN P-05, ikan seurukan, ikan bileh, ikan nila, ikan mas, ika patin, ikan lele, udang galah, pupuk urea, pupuk kalium, DMA (obat anti rumput liar), jaring (pagar areal persawahan), pellet dan probiotik. Alat yang digunakan dalam penelitian ini adalah: cangkul, ember, timbangan, mistar, parang, tali rapiah, terpal, map plastik, label, meteran, jaring pengaman, kamera, dan alat tulis menulis.

\section{Prosedur Kegiatan}

Kegiatan pertama kali adalah dilakukan pengolahan tanah di areal persawahan yang akan dijadikan budidaya ikan sistem minapadi dengan mengunakan cangkul untuk menggemburkan tanah dan memudahkan penenaman padi. Selanjutnya Pembentukan kemalir untuk pemeliharaan ikan lokal dengan lebar $50 \mathrm{~cm}$ dan kedalaman $50 \mathrm{~cm}$. Areal perawahan dilakukan pemagaran dengan jaring agar tidak terserang hama dan penyakit pada ikan lokal dan padi. Sebelum dilakukan proses penanaman padi, terlebih dahulu dilakukan pembentukan garis tanam yang lurus dan jelas dengan cara menarik alat garis tanam yang sudah dipersiapkan sebelumnya serta dibantu dengan tali yang dibentang dari ujung ke ujung lahan. Kemudian menyiapkan bibit padi yang digunakan merupakan varietas unggul (MAPAN P-05) 
selama 20 hari. Bibit padi yang digunakan sebanyak 2-3 bibit per lubang tanam pada perpotongan garis yang sudah terbentuk. Proses penanaman padi menggunakan sistem tanam padi legowo 4:1 yang merupakan hasil terbaik (Bobihoe, 2013) yaitu untuk 4:1 cara tanam padi yang memiliki 4 barisan tanaman kemudian diselingi oleh 1 baris kosong dimana jarak tanam adalah $25 \mathrm{~cm}$. Proses penebaran ikan lokal sebanyak 7 spesies dilakukan setiap petakan per jenis dengan padat tebar 500 ekor/petakan setelah 20 hari penanaman padi dilakukan. Memberikan pakan pellet jenis F-999 (ikan) dan gold coin (udang galah) secara ad-libitum dengan frekuensi $2 \mathrm{x}$ sehari. Pemanenan dilakukan ketika 90\% gabah menguning atau dilakukan 10 hari sebelum panen padi dengan cara mengeringkan petakan sawah terlebih dahulu kemudian ikan ditangkap secara perlahan-lahan dengan cara menyeser ikan dan udang secara total

\section{HASIL DAN PEMBAHASAN \\ Proses Budidaya Ikan Lokal Sistem Minapadi Legowo}

Proses budidaya ikan lokal di areal persawahan yang dijadikan budidaya ikan sistem minapadi dilakukan pada areal persawahan dengan debit air selalu ada sepanjang waktu atau menggunakan irigasi. Selain untuk mengairi sawah juga untuk pemeliharan ikan dan udang dan juga kualitas air yang terbaru akan menjadikan pertumbuhan ikan yang sangat baik. Hal ini sesuai dengan pendapat Sudiarta et al., (2016) yang menyatakan bahwa model minapadi cukup efisien dan efektif untuk diterapkan pada sawah irigasi yang ketersediaan airnya selalu ada untuk pertumbuhan padi dan ikan.

Syarat lokasi yang baik untuk minapadi tersebut kemudian dijadikan areal persawahan minapadi. Sawah yang digunakan dengan luas per petak adalah $5 \times 10$ $\mathrm{m}^{2}$ sebagai percontohan. Sebelum memulai kegiatan, terlebih dahulu dilakukan penggemburan tanah dengan menggunakan cangkul. Hal ini bertujuan untuk menguapkan gas beracun dan juga unsur hara di dalam tanah, agar lebih subur serta untuk memudahkan bercocok tanam padi. Tujuan pengolahan tanah menurut Nurhayati et al., (2015) menyatakan bahwa pengolahan tanah dalam minapadi berfungsi ganda yaitu untuk persiapan tumbuhnya padi, juga menumbuhkan mikroorganisme sebagai makanan ikan.

Selain pengolahan tanah sawah, dilakukan juga membuat kemalir dengan menggunakan cangkul. Hal ini bertujuan selain untuk wadah pemeliharaan ikan agar terhindar dari panasnya matahari secara langsung, juga untuk mengatasi hama berupa keong serta untuk memudahkan pada saat pemanenan ikan. Menurut Hadi dan Astuti, (2013) tujuan kemalir adalah melindungi ikan dari serangan hama serta bahaya kekeringan yang disebabkan oleh penguapan yang tinggi. Selokan atau kemalir ini dibuat melintang/horizontal dan sejajar pematang dengan lebar 1 meter serta kedalaman 50-70 $\mathrm{cm}$. Pembentukan kemalir untuk pemeliharaan ikan lokal dengan lebar $50 \mathrm{~cm}$ dan kedalaman $50 \mathrm{~cm}$

Areal persawahan dilakukan pemagaran dengan jaring agar tidak terserang hama dan penyakit pada ikan lokal dan padi. Pemasangan jaring dilakukan pada tepi atau sekitar sawah (pagar) dan juga pada atas padi untuk menghindari serangan hama berupa burung. Menurut Hadi dan Astuti, (2013) hama yang menyerang padi 
dan ikan adalah burung, ular atau musang air/berang-berang dan keong mas (Hidayat, 2018). Hama selain merusak/memakan/pesaing juga pembawa penyakin/agen bagi kehidupan ikan.

Selanjutnya sebelum dilakukan proses penanaman padi, terlebih dahulu dilakukan pembentukan garis tanam (legowo) yang lurus dan jelas dengan cara menarik alat garis tanam yang sudah dipersiapkan sebelumnya serta dibantu dengan tali yang dibentang dari ujung ke ujung lahan.

Bibit padi yang digunakan merupakan varietas unggul jenis MAPAN P-05 yang disemai selama 18-20 hari (Hidayat, 2018). Bibit padi yang digunakan sebanyak 2-3 batang per lubang tanam pada perpotongan garis yang sudah terbentuk. Proses penanaman padi menggunakan sistem tanam padi legowo 4:1 (Bobihoe, 2013) yaitu untuk 4:1 cara tanam padi yang memiliki 4 barisan tanaman kemudian diselingi oleh 1 baris kosong setiap petak dimana jarak tanam adalah $25 \mathrm{~cm}$.

Proses penebaran ikan lokal dilakukan setiap petakan per jenis dengan padat tebar 500 ekor/petakan setelah 20 hari penanaman padi dilakukan. Menurut BPTP Sulawesi Barat, (2016) penebaran benih ikan setelah penanaman padi dengan tujuan untuk menghindari obat-obatan atau pupuk. Penebaran benih ikan dilakukan pada sore hari secara perlahan-lahan agar ikan tidak mengalami stress akibat perubahan lingkungan.Pemberian pakan pellet jenis F-999 (ikan seurukan) dan gold coin (udang galah) secara ad-libitum dengan frekuensi 2 x sehari.

Pemanenan dilakukan ketika 90\% gabah menguning atau dilakukan 10 hari sebelum panen padi dengan cara mengeringkan petakan sawah terlebih dahulu kemudian ikan ditangkap secara perlahan-lahan dengan cara menyeser ikan dan udang secara total.

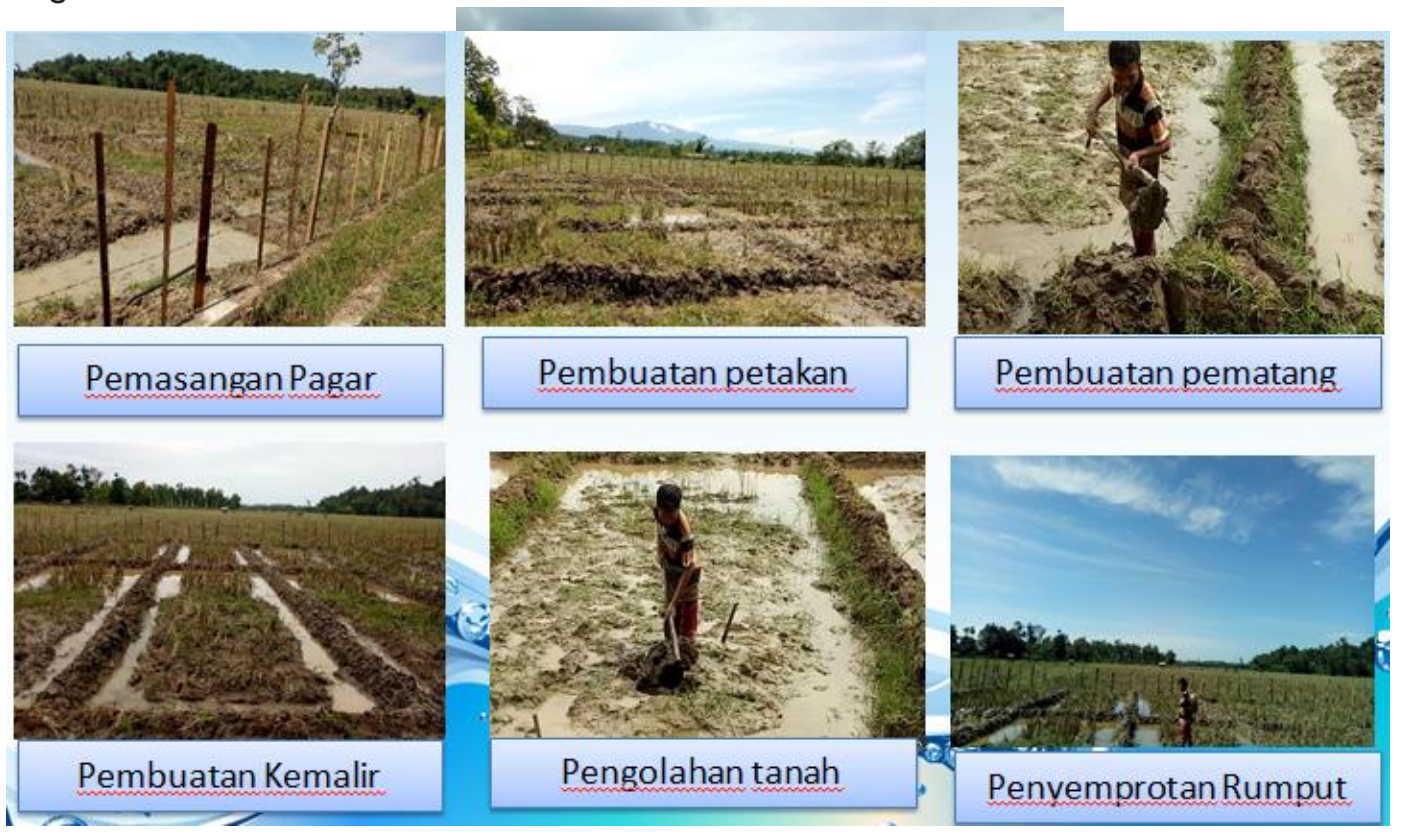

Gambar 1. Persiapan Lahan 

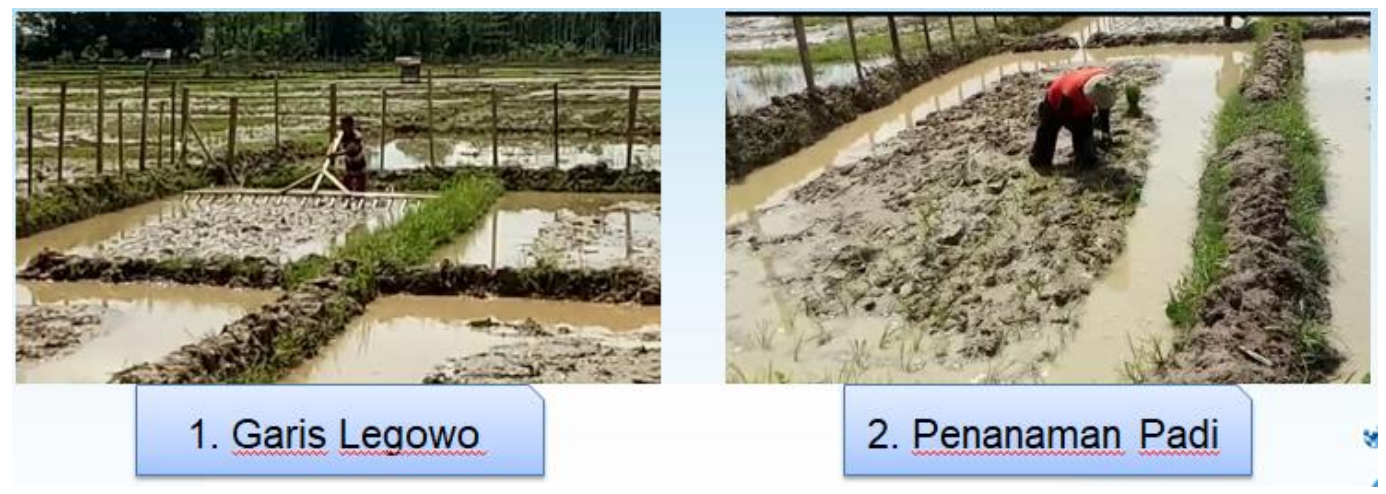

Gambar 2. Proses penenaman Padi

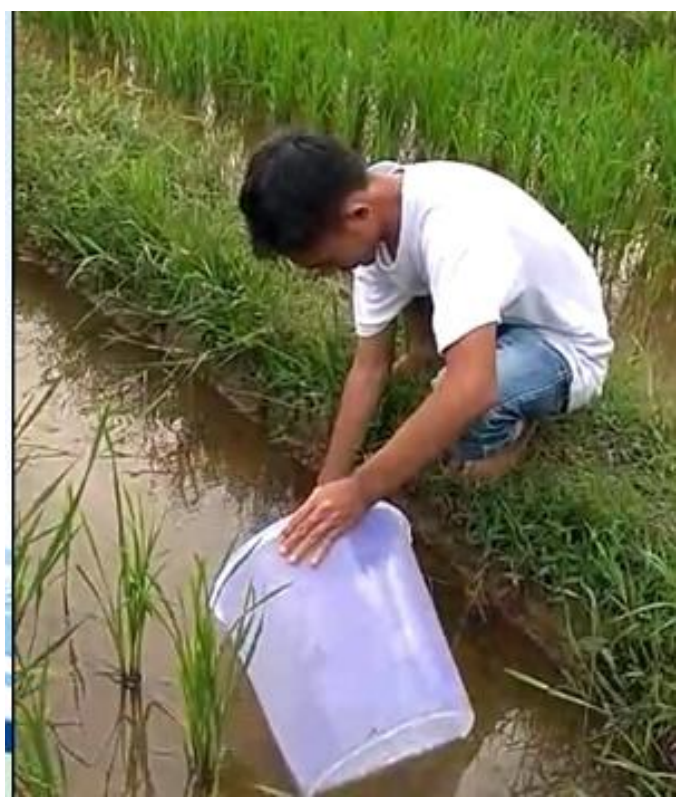

Gambar 3 Penebaran 7 (tujuh) spesies ikan

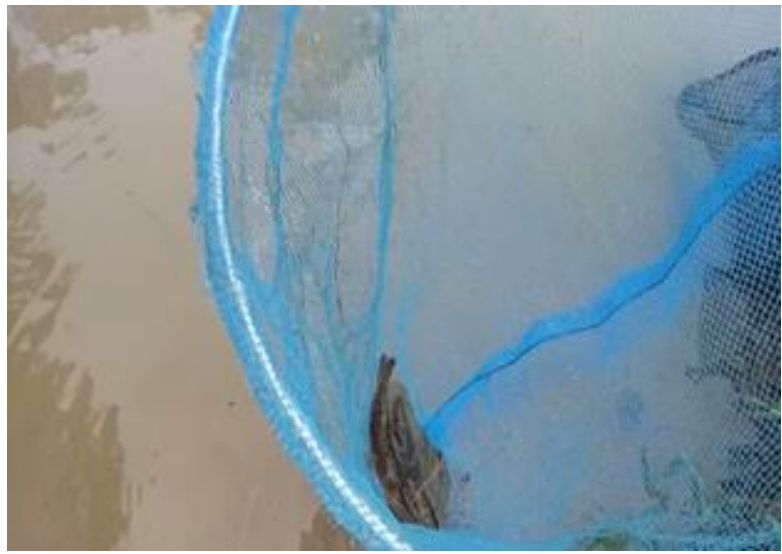

Gambar 4 Prosen Pemanenan Ikan 


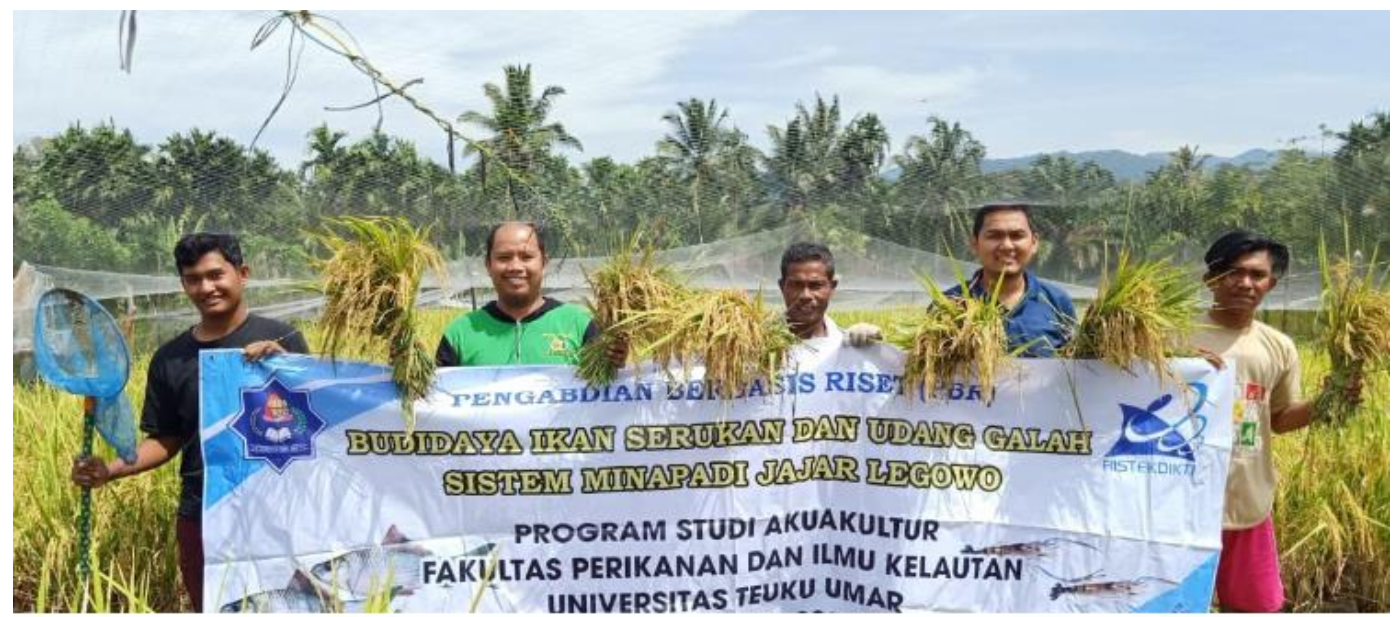

Gambar 5. Proses Pemanenan Padi dan ikan

\section{Produksi Padi Dan Ikan}

Hasil yang diperoleh oleh mitra dapat digambarkan kondisi sebelum dan sesudah mendapatkan pengabdian. Kondisi kelompok petani sebelum mendapatkan pengabdian belum menerapkan system legowo dan juga belum pernah juga di terapkan system minapadi bai di desa tersebur secara khusus maupu di tingkat Kecamatan dan Kabupaten. Setelah petani mendapatkan pengabdian kelompok petani baru merasakan dampak yang baik dari segi hasil . dimana produksi padi dapat meningkat dan keuntungannya juga berlipat setelahmenerapkan system minapadi.
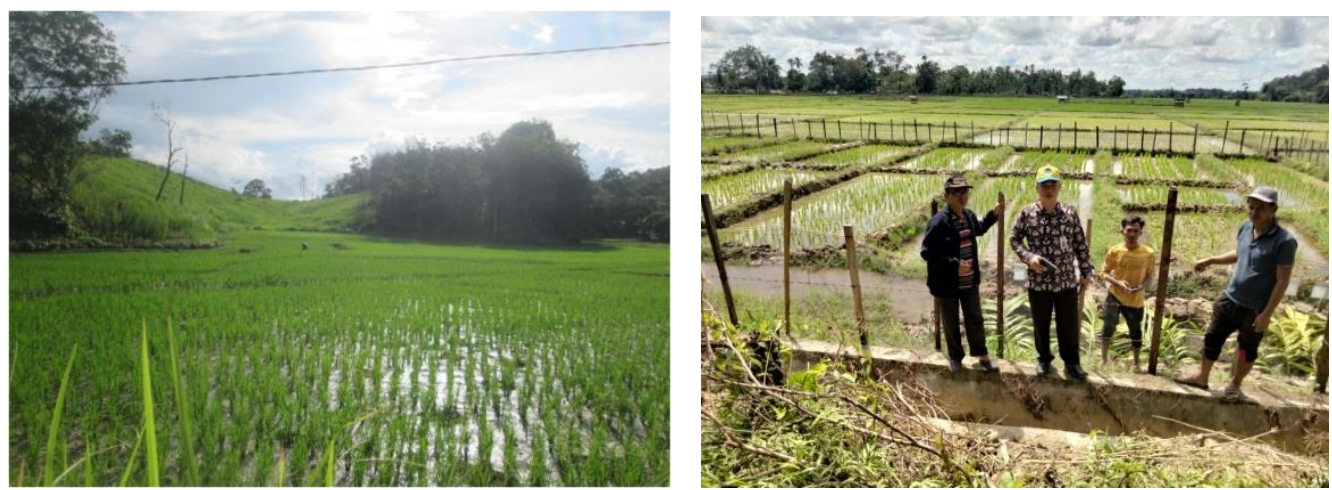

Gambar 6. Kondisi tanpa legowo (kiri) kondisi berlegowo dan minapadi (kanan)

Hasil produksi padi dengan sistem minapadi legowo dapat dilihat pada Tabel 1 dibawah ini:

Tabel 1. Hasil produksi padi sistem minapadi legowo

\begin{tabular}{lcccc}
\hline \multicolumn{1}{c}{ Model } & $\begin{array}{c}\text { Produksi Padi } \\
\text { (Sudiarta et al., } \\
\text { 2016) }\end{array}$ & satuan & $\begin{array}{c}\text { Produksi Padi } \\
\text { (data diolah) }\end{array}$ & Satuan \\
\hline Tanpa legowo & $2.39^{\mathrm{a}}$ & ton/ha & 13.15 & $\mathrm{Kg} / \mathrm{ha}^{\mathrm{a}}$ \\
Legowo 4:1 & $2.94^{\mathrm{b}}$ & ton/ha & 16.17 & $\mathrm{Kg} / \mathrm{ha}^{\mathrm{b}}$ \\
\hline
\end{tabular}

Keterangan : Angka-angka yang diikuti oleh huruf yang tidak sama berarti berbeda nyata pada taraf nyata $5 \%$ berdasarkan uji BNT 
Menurut Sudiarta et al., (2016) rata-rata produksi padi (ton ha-1) berdasarkan uji BNT menunjukan bahwa perlakuan legowo $2: 1$ memberikan hasil tertinggi bila dibandingkan dengan perlakuan lainnya dengan rata-rata produksi padi sebesar (13.15 kg/ha), dan tidak berbeda nyata dengan perlakuan legowo $4: 1$ sebesar $(2.94$ ton/ha) namun berbeda nyata dengan perlakuan tanpa legowo sebesar $(16.17 \mathrm{~kg} / \mathrm{ha})$.

Hasil keuntungan petani setelah memperoleh program pengabdian tentang minapadi dapat di lihat pada Tabel 2. di bawah ini

Tabel 2. Keuntungan tahun pertama setelah menerima program pengabdian

\begin{tabular}{|l|l|l|l|l|}
\hline \multirow{2}{*}{ Model } & \multirow{3}{*}{ Produksi padi } & \multicolumn{2}{|l|}{$\begin{array}{l}\text { Omzet } \\
\text { lorang/bulan } \\
\text { diolah) }\end{array}$} & \multirow{2}{*}{ Total } \\
\cline { 3 - 4 } & & padi & lkan & \\
\hline Tanpa legowo & 2.39 ton/ha & $1,434,000$ & 0 & $1,434,000$ \\
\hline Legowo 1:4 & 2.94 ton/ha & $1,764,000$ & 200,000 & $1,96,4000$ \\
\hline
\end{tabular}

Keuntungan yang didapat oleh petani dari sistem minapadi (Akbar,2017) :

1) Meningkatkan pendapatan petani padi sawah yang mengalami kegagalan panen akibat hama wereng, karena dengan adanya ikan disawah akan mengonsumsi hama wereng, yang jatuh air akibat gerakan ikan.

2) Membantu mempercepat perbaikan lingkungan karena dengan mina padi akan menguragi gas metan yang dibuang dari sisa pemupukan.

3) Mengemat penggunaan pupuk.

4) Peningkatan konsumsi ikan guna perbaikanj gizi keluarga.

5) Diperoleh dua macam produksi sekaligus sehingga dapat meningkatkan pendapatan petani padi sawah.

6) Petani menjadi lebih rajin mengawasi sawahnya ,karena harus mengecek air yg masuk kesawah dan mengecek saring yg di pasang agar ikan tidak keluar.

7) Memperbaiki struktur tanah, karena ikan dalam mencari makan membolak balik tanah.

8) Meningkatkan potensi lahan sawah yang ada.

9) Dapat menekan pertumbuhan gulma, menguragi serangan hama dan penyakit, dan dapat meningkatkan musuh alami bagi tanaman, dan

10) Kotoran ikan merupakan pupuk organik bagi tanamam padi.

\section{KESIMPULAN DAN SARAN \\ Kesimpulan}

Potensi lahan sawah irigasi di Kecamatan Pante Ceureumen secara teknis memenuhi syarat untuk pengembangan minapadi. Berdasarkan hasil dan pembahasan dapat disimpulkan bahwa sistem tanam jajar legowo 4:1 memberikan pengaruh nyata terhadap parameter hasil produksi padi yaitu $(16.17 \mathrm{~kg} / \mathrm{ha})$. Sedangkan Produksi ikan yang di budidayakan (7 spesies) yaitu ikan serukan, ikan bileh, ikan nila, ikan mas, ikan patin, ikan lele dan udang galah. Ke-7 spesies tersebut mampu berkembang dan dibudidayakan dengan baik. 


\section{Saran}

Perlu dilakukan penelitian lebih lanjut tentang sistem tanam jajar legowo pada jarak tanam yang berbeda dengan kepadatan populasi ikan sistem minapadi, terhadap pertumbuhan dan produksi padi dan ikan.

\section{UCAPAN TERIMA KASIH}

Riset penulis dibiayai oleh DRPM Kemendikbud dan juga LPPM dan Penjaminan Mutu Universitas Teuku Umar serta Program Studi Akuakultur Fakultas Perikanan dan Ilmu Kelautan.

\section{DAFTAR PUSTAKA}

Akbar, A. 2017. Peran Intensifikasi Mina Padi Dalam Menambah Pendapatan Petani Padi Sawah Digampong Gegarang Kecamatan Jagong Jeget Kabupaten Aceh Tengah. Jurnal S. Pertanian 1 (1) : 28 - 38

Balai Pengkajian Teknologi Pertanian Sulawesi Barat. 2016. Teknologi Mina Padi dengan Sistim Tanam Jajar Legowo. Balitbangtan Sulawesi Barat . Mamuju

Bobihoe, J. 2013. Sistem Tanam Padi Jajar Legowo. Balai pengkajian teknologi pertanian (BPTP) Jambi. ISBN : 978-602-1276-01-3

Dinas Kelautan dan Perikanan Aceh. 2015. Identifikasi Jenis-Jenis Ikan Endemik Di Perairan Aceh Wilayah Barat Selatan (Aceh Barat). Laporan Akhir. Banda Aceh

Hadi, P dan Astuti, U.P. 2013. Pemeliharaan Ikan Bersama Padi Di Sawah (Mina Padi), Sebuah Potensi Keuntungan Ganda Untuk Petani Di Provinsi Bengkulu. Dinas Pertanian Provinsi Bengkulu

Hidayat, M.N. 2018. Pembesaran Ikan Nila (Oreochromis niloticus) Dengan Sistem Mina Padi Pada Kelompok Ngudi Rejeki, Kec.Tawangsari, Desa Dalangan, Kab.Sukoharjo. Laporan Praktik Integrasi. Program Studi Teknologi Akuakultur Jurusan Teknologi Pengelolaan Sumberdaya Perairan Sekolah Tinggi Perikanan Jakarta

Mahendra. 2015. Kombinasi Kadar Kalium Dan Salinitas Media Pada Performance Juvenil Udang Galah (Macrobrachium rosenbergii de Man). Jurnal Perikanan Tropis. 2(1): 55-71

Mahendra dan Gazali, M. 2017. Penambahan Kalium untuk Meningkatkan Kelangsungan Hidup dan Pertumbuhan Juvenil Udang Pisang (Panaeus Spp). Prosiding Simposium Nasional Perikanan Dan Kelautan. Meulaboh

Mahendra dan Supriadi. 2019. Laju Pertumbuhan Larva Ikan Seurukan (Osteochilus vittatus) Dengan Pemberian Kuning Telur Unggas. Jurnal Akuakultura

Nurhayati, A., Rustikawati, I dan Maulina, I. 2015. Analisis Optimalisasi Minapadi Yang Berkelanjutan (Suatu Kasus di Kecamatan Ciparay Kabupaten Bandung Provinsi Jawa Barat). Fakultas Perikanan dan Ilmu Kelautan,Universitas Padjadjaran

Saputra, F. dan Mahendra, 2018. Pemeliharaan Ikan Gabus Lokal (Channa sp.) Pada Wadah Yang Berbeda Dalam Rangka Domestikasi Di Daerah Arongan Lambalek, Kabupaten Aceh Barat, Provinsi Aceh. Laporan Akhir. Meulaboh 
Sudiarta, I.M., Syam'un, E dan Syamsuddin, R. 2016. Pertumbuhan Dan Produksi Tanaman Padi Serta Produksi Ikan Nila Pada Sistem Tanam Jajar Legowo. J. Sains \& Teknologi, 16 (1): $70-80$.

Zulfadhli, Z., \& Fadhillah, R. (2019). Domestikasi Ikan Bileh (Rasbora sp) Asal Perairan Aceh Barat Dalam Wadah Budidaya Berbeda. Jurnal Perikanan Tropis, 6(2), 101-107. 